\title{
O SILENCIAMENTO DA MULHER NO DISCURSO DO AMOR CORTÊS
}

\section{Ana Beatriz Fernandes Ferreira Domingues ${ }^{(*)}$}

Resumo: Tradicionalmente o discurso amoroso medieval, mais especificamente, o amor cortês difundido na França do século XII é visto como o lugar de dominação feminina. De acordo com as regras desse jogo, a mulher deve ocupar a posição de suserana, enquanto ao homem cabem os serviços de vassalo. Repete-se no âmbito amoroso as normas que regem a sociedade feudal. Porém, analisando as condiçōes de produção do discurso amoroso medieval, observa-se que, sociohistoricamente, o sujeito medieval é regido por uma formação discursiva que the impõe dizer e significar de acordo com o que prescreve a ideologia cristã. É assim que encontramos uma posição-sujeito feminina que é "falada" pelo punho masculino, melhor dizendo, segundo a visão de mulher que os clérigos propagaram durante a Idade Média. Portanto, no discurso do amor cortês, observa-se o silenciamento da mulher, pois os dizeres possíveis na arte da sedução não consideram a vontade do sujeito empírico feminino. A voz que ecoa naquele discurso é apenas masculina, já que reflete o ponto de vista dos religiosos da época, responsáveis por ensinar como devem se portar homens e mulheres na arte da sedução.

Palavras-chave: Discurso; ideologia; posição-sujeito feminino; Idade Média; silenciamento

Abelardo e Heloísa. Tristão e Isolda. Lancelot e Guenièvre. Personagens fictícios? Em parte sim, porém, exemplos universais de histórias de amor. Sentimento natural, o amor, para os humanistas, é o principal requisito da plenitude do ser humano. Tal sentimento (como o concebemos hoje), segundo os franceses, foi inventado em suas cortes medievais do século XII, sob o signo de um jogo: o jogo do amor cortês. Para jogá-lo, era eminente que se conhecessem as suas regras, caso contrário, a arte de amar não se realizava.

(*) Professora da Universidade Federal Fluminense. Mestra em Língua Portuguesa e Lingüística pela PUC/ Rio de Janeiro. 
Nesta arte, o amante deve se mostrar submisso à amada e exprimir o desejo de ser aceito como seu vassalo, oferecendo-lhe incansavelmente os seus serviços. A relação de vassalagem que permeia o sistema sócio-econômico medieval, o feudalismo, transferese para o âmbito dos relacionamentos amorosos. Cabe, então, à mulher conceder ou não a seu servidor a recompensa que ele espera, ou seja, a promessa de amá-lo: primeiro estágio do código de conduta amorosa vigente durante a Idade Média.

Contudo, por que surge tal código? Apenas para a diversão das cortes francesas? Quem são os criadores da literatura cortês? De que forma o jogo do amor cortês tornou-se uma etapa no percurso que conduz à perfeição viril? Essas e outras questões norteiam esta breve reflexão sobre o jogo do amor cortês, mais precisamente, sobre os sujeitos que o "jogam" e as condições sócio-históricas que produzem o discurso amoroso medieval.

Para viabilizar a análise desse jogo amoroso, recorremos a alguns conceitos propostos pela Análise do Discurso francesa, a saber: o conceito de forma-sujeito, que compreende as noções de posiçãosujeito e de formação discursiva, necessárias para entendermos como o discurso amoroso medieval é permeado pelas formas de silêncio, principalmente, pela política do silenciamento.

A análise do discurso (AD) não se interessa apenas pela língua ou pela gramática, mas, acima de tudo, pelo discurso que, segundo Orlandi (2002, p. 15), "etimologicamente, tem em si a idéia de curso, de percurso, de correr por, de movimento. O discurso é assim palavrä em movimento, prática de linguagem: com o estudo do discurso observa-se o homem falando."

Em consonância com Michel Pêcheux (1995), a AD é uma aventura teórica por unir duas questões, em princípio antagônicas: a ideologia e o inconsciente. Isto é possível, visto que a análise do discurso não trabalha com a noção de indivíduos, mas com sujeitos historicamente determinados. A AD se distancia, portanto, da concepção de sujeito empírico, aquele que sabe e domina o que quer dizer, e aproxima-se da noção de sujeito descentralizado, ou seja, que tem a ilusão do domínio do dizer, mas que é afetado por uma determinada formação social que the impõe o que deve ser dito.

Tal qual o sujeito, o discurso também não é empírico para a AD, pois não se reduz ao texto, à sua extensão material. O discurso é um 
objeto teórico que se relaciona com o exterior, ou seja, em que língua e história caminham juntas. Portanto, entender o seu funcionamento linguiístico é examinar as condições em que o discurso foi produzido.

\section{O sujeito na história: a noção de forma-sujeito}

A questão do sentido norteia os estudos que tomam o discurso como objeto de análise. Para a $\mathrm{AD}$, o sentido pode ser definido como "relação a", ou seja, não há um sentido único, verdadeiro, mas o sentido que se constrói a partir de determinadas condições. Esta definição de sentido nos conduz a uma outra, a saber, o que se entende, em AD, por forma-sujeito.

O termo foi utilizado pela primeira vez por Althusser que o definiu como sendo "a forma de existência histórica de qualquer indivíduo, agente das práticas sociais" (PÊCHEUX, 1995, p.183). A forma-sujeito corresponde ao fato de "a interpelação do indivíduo em sujeito de seu discurso se efetuar pela identificação (do sujeito) com a formação discursiva que o domina" (ibidem, p.163). Assim, a noção de forma-sujeito depende de uma relação, ou seja, a relação do sujeito com as condições de produção do discurso. O sujeito se constitui em relação ao Outro, à memória do dizer, aos outros dizeres que o antecedem. Sendo assim, discutir o conceito de forma-sujeito pressupõe compreender o que na $\mathrm{AD}$ se entende por condições de produção do discurso, formação discursiva, interdiscurso e intradiscurso.

As condições de produção do discurso referem-se à exterioridade, à conjuntura sócio-histórica em que o discurso foi produzido e ao lugar social em que seu sujeito está inscrito. Assim, o conceito de condições de produção engloba o de formação discursiva. uma vez que esta "determina o que pode e deve ser dito" (PÊCHEUX. 1995 , p.160) pelo sujeito em dada conjuntura sócio-histórica. Contudo, é importante ressaltar que aquilo que é dito ou pode ser dito pelo sujeito só faz sentido pois é determinado pela ideologia que está em jogo em um dado processo sócio-histórico. Portanto, o conceito de formação discursiva está relacionado ao de formação ideológica, o que desmistifica a idéia de transparência da linguagem e ratifica a necessidade de se considerar os processos sócio-históricos como constitutivos não do sentido, mas dos efeitos de sentido. Segundo Indursky (1998), os efeitos de sentidos dos discursos derivam "do lugar que os sujeitos desses discursos ocupam na formação social, em 
virtude da formação discursiva em que se inscrevem." Ainda segundo a autora (op.cit., p.15), "é isto que autoriza afirmar que o sujeito, em Análise do Discurso, "é um lugar de significação historicamente constituído' (ORLANDI, 1996, p. 37)." O termo histórico é utilizado pela $\mathrm{AD}$ não com a acepção de seqüência cronológica, mas como produção simbólica que organiza, discursivamente, os diferentes sentidos referentes às relações de poder presentes em uma dada formação social.

Os conceitos de interdiscurso e intradiscurso são pertinentes ao conceito de forma-sujeito, uma vez que se referem também à noção de formação discursiva. Segundo Pêcheux (1995), a formação discursiva que veicula a forma-sujeito é a dominante em meio a um conjunto de formações discursivas que constitui o sentido. A constituição do sentido, ou seja, o interdiscurso, pode ser representada como um eixo vertical em que se apresentam todos os dizeres já-ditos e esquecidos. Já o intradiscurso refere-se ao eixo horizontal, àquilo que estamos dizendo em determinado momento, sob certas condições. A relação entre o interdiscurso (o já-dito) e o intradiscurso (o que se está dizendo) corresponde à constituição do sentido e à sua formulação.

O conceito de forma-sujeito remete-nos também ao de posição-sujeito. A tomada de posição por parte do sujeito é um efeito da forma-sujeito, na medida em que deriva não dos lugares empíricos que os sujeitos podem ocupar socialmente, mas da formação imaginária que perpassa esses lugares. A posição-sujeito resulta de um mecanismo imaginário que produz imagens dos sujeitos dentro de uma conjuntura sócio-histórica. Daí, afirmar-se em AD que "as palavras mudam de sentido segundo as posições daqueles que as empregam. Elas ‘tiram' seu sentido dessas posições, isto é, em relação às formações ideológicas nas quais essas posições se inscrevem” (ORLANDI, 2000, p.42).

Se, para a AD, o sujeito se constitui a partir de uma interpelação ideológica correspondente a uma determinada formação discursiva, em nossa sociedade capitalista, tal sujeito se constitui como sujeito de direito, aquele que, ao mesmo tempo que se diz autônomo, responsável pelo seu dizer, é cerceado por condições externas que determinam os seus direitos e deveres. Um sujeito livre, mas também submisso. Todavia, um olhar diacrônico sobre essa questão revela que, historicamente, o sujeito jurídico surge a partir do 
momento em que há uma transformação nas relações sociais, melhor dizendo, nos modos de produção que regem a história do mundo ocidental.

Segundo Haroche (1992), o termo "sujeito" surge no século XII designando aquele que se submete a uma autoridade soberana. $O$ sujeito medieval, portanto, não é livre, mas sim dependente, dominado. A autora (p. 179) alude ao trabalho de M. Miaille que, em sua Introduction critique au droit, afirma serem as relações entre o servo e o senhor, no feudalismo, "explicáveis não diretamente pela economia, mas por um laço de dependência pessoal", o que elimina a possibilidade de existência de um sujeito de direito durante a Idade Média. O sujeito medieval assujeita-se a uma fé cega, ao aparelho religioso que reprime o seu desejo, que lhe nega a ilusão de liberdade característica do sujeito de direito. É sob os mecanismos da crença religiosa que o sujeito medieval se reconhece e assume posições sociais que determinam o seu dizer.

\section{O discurso amoroso medieval: o "silenciamento" da mulher}

Segundo o medievalista francês, George Duby (2001), tornouse banal afirmar que o amor - esse sentimento que nos move/imobiliza, nos une/separa, nos alegra/entristece - foi inventado pelos franceses, mais especificamente pela alta nobreza da França, no século XII. Banal, mas não menos verdadeiro, pois muitos documentos da época atestam o ritual amoroso como código vigente nas relações afetivas entre dois sexos, porém fora do quadro conjugal. À medida que, no século XII, a Igreja estabelece rígidos parâmetros para o matrimônio, exclui-se da relação conjugal toda e qualquer manifestação de afetividade. Ao marido cabe o domínio de sua mulher; a esta cabe a sujeição ao seu dono e senhor.

É, portanto, nesse imaginário, que surge o que se convencionou chamar de jogo do amor cortês, uma doutrina que, como observa Foucault (1998, p.43), "liga os indivíduos a certos tipos de enunciação e lhes proíbe, consequientemente, todos os outros, mas se serve, em contrapartida, de certos tipos de enunciação para ligar indivíduos entre si e diferenciá-los, por isso mesmo, de todos os outros."

Doutrina sim, pois corresponde a regras de conduta amorosa, elaboradas nas cortes dos maiores príncipes da França medieval, e que determina o que deve ou não ser dito por aqueles que desejam 
aprender a arte da sedução. Os príncipes franceses acreditavam ser responsáveis pela educação dos homens e mulheres que se reuniam em torno deles. Assim, o palácio do rei era uma escola de boas maneiras e as obras compostas, durante o século XII, possuíam uma função pedagógica. Era necessário conter os instintos dos “jovens”, ou seja, dos cavaleiros que, por não serem filhos primogênitos, não possuíam o direito de casar. Para que cessassem os raptos de damas da corte, por exemplo, coube aos príncipes regulamentar, encerrar as investidas dos guerreiros dentro de um sistema de conveniências que ensinaria aos cavaleiros outras palavras que não blasfêmias ou gritos de reunir tropas, mas sim como não ser rude com as damas, como agradá-las. Mas a quem caberia a tarefa de organizar as regras, os passos dos homens e das mulheres na arte da cortesia? Quais os tipos de enunciação permitidos nessa doutrina?

Os criadores da doutrina do amor cortês foram homens da Igreja. A eles cabia não só a tarefa de organizar os ofícios da capela real, mas também, como observa Duby (2001, p.121), "de introduzir nos usos profanos os procedimentos e os saberes, os preconceitos, as maneiras de pensar", como também a imagem da dama, ou seja, a mulher como Eva: a pecadora, a que conduz o homem à heresia, a que tenta e que deve ser dominada, controlada, vigiada pelo seu senhor. E é essa mesma mulher que, no jogo do amor cortês, terá um papel central: é ela o objeto do desejo masculino; ela, o prêmio que o cavaleiro almeja; ela, a que deverá controlar os impulsos masculinos, fazendo com que se respeitem os estágios no desenvolvimento da arte da sedução.

Na teoria do amor cortês, a mulher é equiparada a uma suserana, pois o amante deve se mostrar submisso a ela e exprimir o desejo de ser aceito como seu vassalo, oferecendo-lhe incansavelmente seus serviços. A relação de vassalagem que permeia o sistema sócioeconômico medieval, ou seja, o feudalismo, transfere-se para o âmbito dos relacionamentos amorosos, determinando as posições que o sujeito medieval deve assumir nesse imaginário que o rege, nesse código de conduta pautado no assujeitamento a um laço de dependência pessoal e não a um modo de produção. No jogo do amor cortês, é então o homem que se assujeita à mulher, pois a esta delega-se o direito de conceder ou não a seu servidor a recompensa que ele espera, ou seja, a promessa de amá-lo. Tal amor em nada se assemelha ao amor platônico, uma vez que o código do amor cortês sugere estágios que os amantes não devem 
infringir: primeiro, concede-se a esperança de amar; segundo, oferta-se um beijo; terceiro, deixa-se fruir os abraços mais íntimos; quarto, a entrega integral dos amantes se realiza.

É com o intuito de ensinar a arte da cortesia que surge, em 1186, um Tratado do amor cortês. Os textos que compõem o Tratado apresentam o objetivo não só de informar sobre a arte da sedução como também de persuadir seus leitores de que, agindo conforme as regras específicas do jogo, pode-se conseguir o prêmio maior: o amor da mulher cortejada. Mas quem escreve esse Tratado? André Capelão, um clérigo que presta seus serviços ao condado de Champagne. A menção do autor não nos interessa aqui como o indivíduo falante, o sujeito empírico que escreveu o texto, mas como um princípio de agrupamento do discurso. Para a $\mathrm{AD}$, a função-autor confere uma unidade coerente ao discurso, uma identidade, uma individualidade. A autoria é, portanto, uma função discursiva do sujeito e se distingue de outras funções, como as de locutor - o "eu" do discurso - e de enunciador. No dizer de Orlandi (2002, p.75),

se o locutor se representa como eu no discurso e o enunciador é a perspectiva que esse eu assume, a função discursiva autor é a função que esse eu assume enquanto produtor de linguagem, produtor de texto. Ele é, das dimensões do sujeito, a que está mais determinada pela exterioridade - contexto sócio-histórico - e mais afetada pelas exigências de coerência, não contradição, responsabilidade etc.

Assim sendo, consideraremos o locutor do Tratado o indivíduo André Capelão, visto que este se apresenta no prefácio do livro, em que também adverte estar escrevendo-o para atender ao pedido de seu amigo Gautier, recentemente ferido pelas flechas de Vênus e ansioso por esclarecimentos sobre a arte de amar. Nas palavras de Duby (2001, p.139):

Gautier sim é um jovem como Lancelot, como Tristão quando encontra Isolda. Ferido pelas flechas do amor, do amor mostrado de imediato como um agressor brutal. ele acaba de entrar na cavalaria dos amantes. Novo recruta. ainda não sabendo bem como segurar as rédeas de seu cavalo, pede ao mestre que o instrua. André compõe para 
ele uma arte, uma coletânea de receitas práticas em que o Aprendiz aprenderá seu ofício.

Na tentativa de dar vida à doutrina amorosa, André apresenta oito diálogos entre homens e mulheres, membros da sociedade medieval, pertencentes a classes sociais distintas. É assim que se exemplifica como um plebeu e uma plebéia, ou um nobre e uma mulher da nobreza, ou ainda um grande senhor e uma dama da pequena nobreza devem se portar na arte da disputa. Os diálogos apresentam, invariavelmente, a estrutura da disputatio, ou seja, um exercício de discussão, muito praticado nas escolas do século XII, que consiste na troca de objeções e respostas acerca do exame crítico de uma questão. Baseia-se nas obras de Aristóteles, configurando-se como um exercício de dialética. Assim, durante os diálogos, os interlocutores respondem uns aos outros sistematicamente, sem muita imaginação, mas com humor e ironia, conferindo à conversação um ar de argumentação escolástica. Vejamos um exemplo elaborado por Capelão (2000, p.25):

O homem: "Ao te dar forma, o ser divino não poderia criar obra mais bem acabada: nada falta à tua beleza, nada à tua discrição; possuis tudo, mas só te falta uma coisa, parece-me: ainda não presenteaste ninguém com teu amor.

No entanto, muito me surpreende permitir o amor que mulher tão bela e distinta sirva por tanto tempo longe de suas hostes. Oh! Se quisesses alistar-te em suas coortes, aquele que distinguisses com teu amor seria feliz entre todos. E se meus méritos me fizessem digno dessa honra, nenhum enamorado do mundo poderia a mim compararse."

A mulher: "Tuas palavras parecem falsas, pois, embora eu não seja bela, tu me elogias como a mais linda das mulheres, e embora eu seja desprovida de distinção, tuas palavras gabam minha discrição. Uma mulher de minha origem não pode ter pretensão a ser sumamente distinta."

Neste fragmento do suposto diálogo entre um plebeu e uma plebéia, observamos a representação de duas posições-sujeito: a masculina e a feminina. À posição masculina cabe a tarefa de elogiar, de dizer o quanto há de discrição na mulher que se almeja cortejar, já 
que esta é a enunciação permitida pela formação discursiva em questão. Porém, já à posição-sujeito feminina confere-se a enunciação da recusa, pautada na falácia dos argumentos utilizados, pois, na formação discursiva em questão, uma plebéia não possui a distinção relativa à nobreza: "Uma mulher de minha origem não pode ter pretensão a ser sumamente distinta." Na posição-sujeito feminina vemos a enunciação de uma das regras básicas que organizam a sociedade medieval: a determinação das "castas", do lugar que devem ocupar os indivíduos que as constituem. Assim, ao sujeito medieval cabe o dizer condizente com a classe social a que pertence, é deste lugar que os discursos são produzidos e os outros dizeres possíveis silenciados.

Quando lemos o diálogo entre dois interlocutores de classes sociais distintas, observamos que a cortesia sequer se efetua, visto que um dos princípios que rege o jogo do amor cortês é enunciado pelo locutor do Tratado (p.37) no capítulo relativo a "quais são as pessoas capazes de amar": não é possível o amor entre amantes de "castas" sociais distintas. Sendo assim, no diálogo entre um plebeu e uma mulher da baixa nobreza, apesar de o locutor do Tratado afirmar que "o amor não tem o hábito de diferenciar os homens por títulos", "só se preocupa em saber quem é capaz de portar suas armas", "o amor calca-se na natureza" e "se o amor leva todos os homens, sejam quais forem, a inflamar-se de paixão, os amantes não devem interessar-se pelas diferenças de classes", observa-se que a recusa feminina de aceitar a cortesia se dá não devido à vontade do sujeito empírico, mas resulta da posição que essa mulher ocupa na sociedade medieval. Assim, à posição-sujeito feminina cabe a reafirmação das regras de conduta amorosa, como observamos no fragmento abaixo:

Haverá audácia maior que a de um homem que, durante toda a semana, se aplica com todas as forças a auferir lucros de seu comércio e que, no sétimo dia, aproveita a folga para tentar apropriar-se dos presentes do amor. transgredir prescrições e anular diferenças sociais estabelecidas entre os homens desde a Antiguiidade? (Ibidem, p.39).

Contudo, cabe-nos ressaltar que a voz feminina que ecoa nos diálogos, na verdade, em nada se aproxima do que supostamente poderia ser falado pela mulher medieval. Esta é "falada" a partir do ponto de vista masculino, melhor dizendo, a partir da visão de mulher 
que os religiosos medievais possuíam. Daí o interesse de um dos maiores medievalistas franceses, George Duby (2001, p.8), em investigar a história das mulheres na Idade Média, mais especificamente, em "captar (...) uma imagem das damas do século XII", produzida pelos padres que falam sobre elas ou até com elas. Segundo aquele autor, a mulher medieval é vista pelos religiosos como "sementes de guerra", são enganadoras diante dos homens, enfeitiçam-nos, sua natureza leva-as a pecar, como comprovou Eva. Assim, o primeiro passo é tomá-las sob tutela, é colocá-las sob o domínio do Senhor, seu marido. É fazer com que assumam uma posição passiva, especialmente nos gestos de amor. Como afirma Duby (2000, p.29), devem ser "objetos que os machos, jovens ou velhos, espreitam, dobram à sua vontade, com os quais brincam." $O$ homem é, portanto, o chefe da mulher, o responsável pelos atos e pensamentos daquela que desposou. Em amor e temor, a esposa deve estar submetida ao marido, como observa André Capelão (2000, p.35), "pois haverá maior dádiva, para uma mulher, do que a de se submeter totalmente à dominação de outrem?"

Desta forma, a partir dos estudos de George Duby, podemos afirmar que a mulher medieval é "silenciada", ou melhor, a posiçãosujeito feminino que se revela no discurso amoroso da Idade Média se significa através da política do silenciamento que sofre. À mulher cabe o dever de dizer uma coisa para não se deixar dizer "outras". Orlandi (1997, p. 11) observa que "há um modo de estar em silêncio que corresponde a um modo de estar no sentido e, de certa maneira, as próprias palavras transpiram silêncio." As palavras que ecoam no jogo do amor cortês, produzidas pelo punho religioso, denunciam o nãodito, o que fazia parte das condições de produção do discurso amoroso, mas que deve ocupar o espaço da memória do dizer. Em outras palavras, os dizeres silenciados promovem efeitos de sentido que ressoam no interdiscurso, mostrando que o sentido não está apenas no enunciado, mas no intervalo que há entre o sentido institucionalizado e aquele que não foi mobilizado, permitido de ser instaurado como o "natural".

O silenciamento feminino, principalmente no que concerne ao discurso amoroso medieval, deve-se ao fato de se obrigar a dizer ou silenciar de acordo com o que é prescrito pela doutrina cristã. Produzse, assim, um recorte em relação ao que se diz e ao que não se diz. Há um jogo de poderes que se caracteriza pela opressão, pela dominação, 
pela dependência da figura feminina em relação ao universo masculino que delimita o dizer, confirmando os limites da formação discursiva dominante na Idade Média.

Neste sentido, o papel de suserana que a mulher assume no jogo do amor cortês nada mais é que uma ilusão de domínio de que se cobrem os sujeitos interpelados pelo discurso religioso. À dama cabe somente o dever de ceder à cortesia, caso esta se desenrole conforme os princípios da doutrina estabelecida no Tratado do amor cortês, código de conduta prescrito de acordo com a ideologia cristã.

Será, então, sob o punho da religião que a prática amorosa passará a ser ensinada, efetivando-se a submissão dos sujeitos a uma determinada formação discursiva: a da ideologia do discurso religioso que rege a sociedade medieval. Orlandi (1997, p.100) observa que uma tal ideologia promove o efeito de completude, evidência dos sentidos que são institucionalizados, "admitidos por todos como natural."

Ao examinarmos o jogo do amor cortês, pudemos discutir como o sujeito medieval se constitui a partir de uma relação de dependência pessoal. Relação esta que perpassa não só o sistema econômico vigente na época, o feudalismo, como também as relações entre os indivíduos que se aventuram na arte da sedução.

Não só essa relação de dependência constitui o sujeito medieval, mas também a formação discursiva que o domina e que determina o que deve ou não ser dito, o que deve ser silenciado, o que faz sentido no discurso amoroso. Assim, observamos que, na Idade Média, a doutrina cristã delimita as enunciações possíveis por parte dos sujeitos que se inscrevem no discurso amoroso. Daí, destacarmos a posição-sujeito feminina que, nos diálogos possíveis no jogo amoroso - ensinados por André Capelão -, denuncia uma política de silenciamento, uma vez que a voz que ecoa no discurso do amor é apenas masculina. Em outras palavras, o sujeito medieval, ao ocupar a posição feminina, não possui uma voz própria, pois é "falado" pela posição masculina. Cabe aos criadores da literatura cortês, ou seja, aos clérigos, ensinar como se devem portar homens e mulheres na arte da sedução, determinar as enunciações possíveis nesta arte. Observamos que a posição-sujeito feminina é realizada, então, de acordo com o ponto de vista dos religiosos da época e não a partir do que o sujeito empírico feminino poderia dizer no jogo do amor cortês. É por isso 
que afirmamos ser o discurso amoroso medieval também uma doutrina que determina e delimita os dizeres possíveis dentro de uma realidade social e historicamente bem definida.

Desvelar, então, os sentidos que se encontram no percurso do dizer e nas suas margens é embrenhar-se na rede de sentidos que constitui o que entendemos hoje por amor que, no dizer de André Capelão (2000, p.11), 'significa 'prender' ou 'ser preso'. Pois quem ama fica preso nas malhas do desejo e deseja prender o outro em seu anzol."

\section{Referência bibliográficas}

DUBY, Georges \& PERROT, Michelle. História cias mulheres: a Idade Média. Porto: Edições Afrontamento, 1990.

DUBY, Georges. Damas do século XII: a lembrança das ancestrais. São Paulo: Companhia das Letras, 1997.

DUBY, Georges. Eva e os padres: as damas do século XII. São Paulo: Companhia das Letras, 2001.

CAPELÃO, André. Tratado do amor cortês. São Paulo: Martins Fontes, 2000.

FOUCAULT, Michel. Vigiar e punir: a história da violência nas prisões. Petrópolis: Vozes, 1977.

FOUCAULT, Michel. Microfísica do poder. Rio de Janeiro: Graal, 1990.

FOUCAULT, Michel. A ordem do discurso. São Paulo: Loyola, 1998. GADET, F. \& HAK, T. Por uma análise automática do discurso: uma introdução à obra de Michel Pêcheux. Campinas: Editora da Unicamp. 2001.

HAROCHE, Claudine. Fazer dizer, querer dizer. São Paulo: HUCITEC, 1992.

INDURSKY, Freda. A análise do discurso e sua inserção no campo das ciências da linguagem. Cadernos do I.L. Porto Alegre, Instituto de Letras, UFRGS, n. 20, p. 7-21, 1998.

LABARGE, Margaret W. La mujer en la Edad Media. Madrid: Nerea, 1989. 
LE GOFF, Jacques \& SCHMITT, Jean-Claude. Dicionário Temático do Ocidente Medieval. São Paulo: Edusc/Imprensa Oficial SP, 2002.

PÊCHEUX, Michel. Semântica e discurso: uma crítica à afirmação do óbvio. Campinas: Unicamp, 1995.

ORLANDI, Eni. Palavra de amor. Caderno de Estudos Linguḯsticos. Campinas, (19): 75-95, jul/dez. 1990.

ORLANDI, Eni. A linguagem e seu funcionamento: as formas do discurso. Campinas: Pontes, 1996.

ORLANDI, Eni. As formas do silêncio: no movimento dos sentidos. Campinas: Unicamp, 1997.

ORLANDI, Eni. Análise de discurso: princípios e procedimentos. Campinas: Pontes, 2002. 